\title{
What May Words Say, or What May Words not Say. A Corpus-Based Approach to Linguistic Action ${ }^{1}$
}

\author{
Montserrat Martínez Vázquez \\ Pablo de Olavide University \\ mmarvaz@upo.es
}

\begin{abstract}
In this paper I present an empirical approach to the analysis of the way English speakers conceptualize the communicative process in English. Most linguistic expressions about language in English are surface manifestations of what Reddy termed the "conduit metaphor". Reddy's model implies several interrelated cognitive associations: words are conceived as containers in which speakers introduce their ideas and send them to listeners, who will take these ideas out of these containers. Central to this model is the metaphor words are containers. It has also been claimed that there are other ways of perspectivizing the language process apart from the notion of containment (Vanparys 1995). In fact, Reddy himself notes that there is approximately a $30 \%$ of metalanguage not based on the conduit metaphor. The pervasiveness of the container metaphor would reasonably be most directly tested in expressions with the lexeme word. In order to measure what falls inside and outside these containers I carry out a corpus analysis of the lexeme word excerpted from the British National Corpus (BNC). The systematic evidence obtained from a large but delimited corpus gives us more reliable information about the frequency and use of this metaphor than an intuition based analysis or an arbitrary search in multi-source corpora.
\end{abstract}




\section{Introduction}

\subsection{Delimitation}

Conceptual metaphor theory claims that there is a general tendency to reify abstract elements. In order to do so we relate them to other concrete experiences with the use of figurative language:

The essence of metaphor is understanding and experiencing one kind of thing in terms of another (Lakoff and Johnson 1980: 5).

The need to apprehend things make us delimit them. When we describe an object to another person we make use of our hands to show shape, proportion, etc. We try to reify it in front of our listener. Delimitedness is an important cognitive device which, as other concepts, leaves its traces in grammar. Lakoff remarks that people assume that concepts like love or anger are presented metaphorically, but they do not realize that other concepts like time, quantity, etc. are understood metaphorically, and are usually part of our grammar:

Most people are not too surprised to discover that emotional concepts like love and anger are understood metaphorically. What is more interesting, and I think more exciting, is the realization that many of the most basic concepts in our conceptual system are also normally comprehended via metaphor--concepts like time, quantity, state, change, action, cause, purpose, means, modality, and even the concept of a category. These are concepts that enter normally into the grammars of languages, and if they are indeed metaphorical in nature, then metaphor becomes central to grammar (Lakoff 1993: 212) (emphasis mine).

Tenny (1987: 113) uses the concept "spatial delimitedness" to explain boundness: a count noun like apple refers to a spatially delimited thing, while snow describes something which is undefined in extent, it has no clear boundaries. However, this concept is not so clear when we consider abstract entities. Whatever makes us think about ideas as delimited and knowledge as an entity lacking boundaries is rather arbitrary. In fact the latter is ruled as a count noun in Spanish (el conocimiento/los conocimientos). These grammatical bounding rules that are valid for nouns are also applied to predicates, and are usually discussed under the rubric of telicity. Atelic activities like mass nouns have minimal parts: a subpart of the event of singing is still an event of singing, if you just sing a part of it you have performed the process of singing, but telic events like sing a song do not; if you only sing a part of a song we can not conclude that you have sung a song. This process has also been observed in the adjectival domain. Wyngaerd (1998) explains that there are also bounded and unbounded adjectives. An intensifier like very that qualifies unbounded scales shows the distinction: you may say the door is very big, but not *the door is very open, since big is not bounded whereas open is.

Delimitedness is, however, not totally fixed in grammar. Mass nouns like atelic predicates can be delimited by means of grammatical devices, like the use of phrasal 
determiners, as in a bottle of water, a piece of meat. But there is a much more direct way of bounding these entities: the use of metonymy. Thus, in a proper context, a restaurant, we may hear two coffees, a lamb and two porks. The SUBSTANCE FOR OBJECT ${ }^{2}$ metonymy makes us relate the unlimited liquid or meat to a limited portion of it as served in a cup or a on a dish without the use of grammatical devices. As Radden (2005: 16) points out "grammatical properties of lexical items apply prototypically, not categorically, i.e. words tend to be flexible with respect to their grammatical properties." He explains the metonymic blending of examples like three beers as cases of what he terms the BOUNDED SUBSTANCE FOR THE SAME KIND OF THAT SUBSTANCE metonymy. Like Tenny, he also emphasizes the spatial nature of this metonymic blending: "The boundaries separating different portions of the substance are thus purely spatial" (2005: 16). Figurative language is here used as a fast delimiting device.

We are bounded physical beings and we tend to assimilate anything unreachable to our closest reality. Central to this idea of boundedness is the concept of container, as Lakoff and Johnson (1980: 29) state:

We are physical beings, bounded and set off from the rest of the world as outside us. Each of us is a container, with a bounding surface and an in-out orientation

Langacker (1991) considers the container metaphor as one of the most influential on our way of thinking:

The concept of a discreet container, whose rigid sides define a sharp boundary between an inside and an outside, underlies both set theory and formal logic, as well as the classic criterialattribute model of categorization (1991: 508).

Our language is consistently adapted to this reification and delimitation procedure. But not all language users conceive the same ways of accessing reality; as a result, not all languages will follow the same procedures. As mentioned above, the grammatical behaviour of abstract or even concrete entities is not necessarily the same in different languages. Thus, knowledge, furniture or news, just to mention some examples, are categorised as mass nouns in English, whereas Spanish speakers face the same entities as grammatically delimited.

\subsection{Creativity and Metonymy}

Language is inherently human, or vice versa, as Wierzbicka (1987: 1) puts it "homo sapiens is, essentially, homo loquens, a speaking being". A definition of man must include the language ability, and any reference to language must necessarily be understood as a reference to human beings. There is, therefore, a metonymic relation between language and man: language is a product of man. Thus, words, for example, are viewed as objects belonging to the person who utters them, as we can see in the first definition of word in the 
Oxford English Dictionary (OED):

I. Speech, utterance, verbal expression. 1. collect. pl. Things said, or something said; speech, talk, discourse, utterance; esp. with possessive, what the person mentioned says or said; (one's) form of expression or language (emphasis mine).

Language is a product of human beings and may be grammatically treated as a personal belonging, therefore metalinguistic lexemes, like word are frequently introduced by the possessive. This personal treatment of language reveals its creative nature. As opposed to a non natural language like a programming language, the user may decide to express his/her ideas or feelings in an unlimited number of ways. Linguistic acts, unlike mathematical formulae, do not have to be accurate. Language users may decide to be efficient or imaginative; they may want to transmit thoughts or feelings. For example, a taxi driver who took me to the airport in a hot summer day in Seville used the following expression:

\section{(1) Estoy harto de volante ("I am fed up of steering wheel").}

The metonymy would be quite insignificant uttered by any driver. The mention of a steering wheel to refer to a vehicle is quite natural, since it is the part of the car with which we have a most direct physical contact when we drive. But for a taxi driver, the steering wheel is not only part of the driving, but also his/her companion during the long hours they wait in line in taxi stands. Metonymy has been described as an "abbreviation device", which "enables us to say things faster, to shorten conceptual distances" (Nerlich, Clark and Todd, 1999: 362). But the metonymy used by the taxi driver is not only the fastest way to say it, but also a creative way of expression, which adds a personal flavour and a feeling that an expression like car would not provide.

On the other hand, the famous "the ham sandwich wants his coffee now" uttered by a waiter in a café is a metonymy probably used as the fastest way to locate the customer. Metonymy here works as a quick identifying device. It requires a lighter cognitive effort than metaphor since it appears within a single domain, following Kövecses (2002: 145) definition:

Metonymy is a cognitive process in which one conceptual entity, the vehicle, provides mental access to another conceptual entity, the target, within the same domain, or idealized cognitive model (ICM).

\subsection{Aims and Methodology}

Since language is such an important activity for human beings it will consistently be a recurrent topic among language users. Its abstract nature, on the other hand, makes it less accessible, so it tends to be described through metaphorical descriptions. Reddy's (1979) influential work on metalanguage (i.e. the language we use to talk about language) is 
conceptualized in terms of what he terms "the conduit metaphor", which comprises three interrelated metaphors: IDEAS ARE OBJECTS, WORDS ARE CONTAINERS, and COMMUNICATION IS SENDING (these containers through a conduit). He estimates that about $70 \%$ of the language we use to talk about the English language is based on this metaphor. Although the examples he offers are convincingly enough of the pervasiveness of this model, his listing of the metalingual resources of English, as he himself claims, is partial. A further search for expressions of this kind, which Reddy claimed to be needed, was performed among others by Goossens et alii (1995). Their systematic search for figurative expressions related to linguistic action in the Longman Dictionary of Contemporary English yielded 1916 entries. Their aim was the analysis of conventionalized rather than creative metaphors. My aim in this paper is also empirical and based on a corpus. But I want to concentrate on one part of the conduit metaphor, the container conceptualization, and for this purpose I will search for what is expected to be one of the most productive source domains of the metaphor, the word. Besides testing the pervasivenes of this concept, I want to find out, what other domains are activated in these figurative exressions. I have chosen a subcorpus of oral English from the BNC to see how much of our daily talk about language involves conventionalized metaphors and how much of it is "creative". It is not the purpose of this analysis to offer a survey of conventional metalinguistic metaphors as found in dictionaries ${ }^{3}$ but rather to zoom into one single source domain for linguistic action and search for other ways of viewing language. Conventionalized metaphors are used automatically without activating figurative reasoning, whereas other metaphoric expressions created ad hoc may better reveal the speaker's perception of language.

This corpus-based approach involves both quantitative and qualitative analysis in the line proposed by Charteris-Black (2004: 34):

Both quantitative and qualitative approaches are necessary for the investigation of metaphor. Qualitative judgements are necessary initially to establish what will be counted as metaphor. Then quantitative analysis can allow us to measure the frequency of a metaphor in a corpus and to estimate the extent to which a particular metaphorical sense of a word form has become conventionalised.

In the following section I offer a brief reflection on language and the elements that take part in the communicative process.

\section{The communicative process}

Since language is such a central part of human beings, references to our speaking abilities abound in our daily life. Curiously enough in El Quijote the third most frequent lexeme is dijo ("said"), and the fourth respondio ("answered").

Speaking is the most direct way of communication. When we speak we make a sound by physically moving our mouths. It is a central claim of conceptual metaphor theory that 
metaphors are based on bodily experience. In this line, we frequently talk about our language metonymically through the organs that take part in speech: tongue, lips and mouth:

(2) There were no medals for Felipe to win for his country but he put Spain on the map, his name on every tongue. (BNC: h\hg\hgk 46)

(3) As Bismarck said, "I have always found the word "Europe" on the lips of those who wanted something from other powers which they dared not demand in their own name'. (BNC: a lamlamk 72)

(4) Malcolm taught me things as well. Things like how not to mouth off about any ideas you might have. (BNC: ala6la6e 54)

There is a general view of speaking as an act of sending air, as in breathing, (5), more emphatically stated through verbs like cough, sigh, gasp, or spit as in (6). The mouth is viewed as a container metonymically understood to discharge words (cf. Martínez Vázquez 2005).

(5) "Darling!" breathed Jay, drawing her close, searching for her adorable lips again, "stay with me. 10.377 (BNC: a a 1 0 \a01 25)

(6) "You've made me mad now!" Simon spat out the words. (BNC: a laclacb 50)

As Rudzka-Ostyn (1988a: 514) observes:

The domains of acoustics and space frequently interact when they extend into speech acts. The interaction is brought on either by a spatial particle or preposition..., or a verb denoting discharge of some substance: (9) Come on, cough it up, we know you are guilty.

\subsection{Communication as transfer}

The transfer idea implied in communication does not necessarily originate from the physically observable fact that we send air in the act of talking; it may rather arise from our conception of communication as a social activity (from Latin communicare, "to share") which involves a second person, the listener, who, following our picture of communication is conceived as a "receiver". Vorlat (1982: 12) emphasizes the need for this element: "In every communication scene a receiver is conceptually required".

Therefore, an interchange of communication involves at least three nuclear elements: sender, message and receiver. Jakobson (1960) completes this picture of the communicative act by remarking that the message has to be related to a context, and must be put into a code common to the speaker and the receiver. Finally a contact enables addresser and addressee to communicate. Dirven et alii (1982:4) offer a wider perspective:

...a sender transfers information to a receiver: this information transfer is presented as a 
message and/or topic or evaluation; the information is transferred via a channel, put down in a code and possibly caught in a textual conveyor. The whole process takes place in a given socio-cultural context, at a specific time and place, in a certain manner and under certain circumstances; the sender may have a certain purpose and the receiver may be affected by the result of the information transfer.

Communication considered as a whole is thus faced as a transfer process. But references to our linguistic acts may focus on any element of the communicative process. We may wish to emphasize the channel, by using a verb of instrument of communication like telephone, (7); concentrate on the speaker's difficulties to express him/herself in examples like (8); focus on the listener's reaction to the process, as in (9), or highlight the mood of the speaker by choosing a manner verb like yell, scream or bark, (10),

(7) Yesterday's bomb went off 20 minutes after $a$ warning was telephoned to Waterloo railway station that there was a device at the Stock Exchange. (BNC: alaklak2 2)

(8) ....and then I shall be loosed from this dumbness that binds my tongue, and I shall be able to say to her what needs to be said, and what as yet I cannot say. (BNC: $k \backslash k 81 \mathrm{k} 8 \mathrm{~s}$ 48)

(9) His sharp tongue and piercing, blue-eyed stare have shot down many an opponent. (Cobuild: newspaper)

(10) The platoon commanders barked their orders to dismount and the vehicles came to an abrupt standstill amongst the enemy. (BNC: a la7\a77 46)

\subsection{The conduit metaphor}

Reddy (1979) made an important step forward in the analysis of the communicative process by claiming that English conceptualizes communication in terms of the conduit metaphor:

(1) language functions like a conduit, transferring thoughts bodily from one person to another.

(2) in writing and speaking, people insert their thoughts or feelings in the words; (3) words accomplish the transfer by containing the thoughts or feelings and conveying them to others.

(4) in listening or reading, people extract the thoughts and feelings once again from the words (1979: 290).

According to this view language is structured around the following metaphors: COMMUNICATION IS SENDING IDEAS, IDEAS ARE OBJECTS, and WORDS ARE CONTAINERS The speaker puts ideas into words and sends them through a conduit to a listener, who takes the ideas out of the words. Reddy supports this theory with examples like the following:

(11) That thought is in practically every other word. [10]

(12) Try to get your thoughts across better. [1]

(13) Whenever you have a good idea, practice capturing it in words. [4] 
(14) Try to pack more thought into fewer words. [6]

He observes that even though there are ways of avoiding these conduit "metaphorisms", which he estimates in a 30 percent of our expressions about language, "this would still not free you from the framework" (1979: 299). In fact, as Lakoff and Johnson state, we are not conscious most of the time that we are using this model:

This[the conduit metaphor] is so much the conventional way of thinking about language that it is sometimes hard to imagine that it might not fit reality. But if we look at what the conduit metaphor entails, we can see some of the ways in which it masks aspects of the communicative process (1980: 11).

In the following section I will proceed with a corpus analysis of the lexeme word in order to find out what is hidden in our linguistic expressions about language.

\section{Corpus analysis}

The present corpus analysis explores the figurative uses associated to the lexeme word in a sample of 471 sentences excerpted from oral texts in the BNC. Oral language has been chosen for its spontaneity. The metonymic extensions of the lexeme word found in this corpus have been grouped into different classes. In order to complete the qualitative and quantitative analysis two larger corpora containing more than 10.000 sentences with word/words extracted from oral and written texts from the BNC will be examined with the help of Wordsmith Tools. Three words to the left of each occurrence will be observed in order to analyse the words which combine with this lexeme (see appendix A and B). When they do not belong to the metalinguistic field its figurative sense will be analyzed.

The lexeme word has been chosen because word forms are central units of language; as such they are taken as representative of linguistic expressions in general. Words may be regarded as semiotic symbols, as in the following definition from the OED:

A combination of vocal sounds, or one such sound, used in a language to express an idea (e.g. to denote a thing, attribute, or relation), and constituting an ultimate minimal element of speech having a meaning as such; a vocable.

As such they are treated as concrete linguistic elements, which may take shape in writing or as sounds produced in speaking. The following examples illustrate these non figurative uses:

(15) Read it. That's the longest word in the dictionary. (BNC: $k \backslash k c \backslash k c e$ 66)

(16) Every time you hear the word election, you start to cringe! (BNC: $k \backslash k c \mid k c n ~ 82$ ) 
Sometimes they are defined temporally or sequentially, identified by the time when they were uttered or by their position in a linear sequence.

(17) Going back to your earlier words about the illustrations and the message... (BNC: flfylfyb93)

(18) The last words my mother found to say... (BNC: flfulfu5 56)

Almost half of the uses of this lexeme are clearly figurative $(45.3 \%)$. The rest of the examples in our corpus are not evidently literal. They are not metaphorical because words are not combined with a lexical item suggesting a source domain outside the linguistic domain. But, most of the associations we find in our corpus are metonymic in nature; either clear metonymies or metonymies derived into metaphors (cf. Goossens 1990 and Barcelona 2003), and metonymies frequently go unnoticed. Besides, some of the examples which were classified as non-figurative at first glance were found to involve some type of nonliteral language. Thus, if we consider for example (18), words are viewed sequentially, as in the order they follow in speech, but at the same time, the sequence may be extended to cover a whole life, so that "last words" designates the final speech act in a person's life. Finally, there is a colloquial phrase of surprise appearing three times in our corpus, which I have not been able to explain:

(19) Oh yes, yes five hundred in a bay. My word! Mm. That's a lot isn't it? You know. Do you still do some of then Len? (BNC: $k \backslash k c \backslash k c 074$ )

The main association found in relation to the lexeme word is one of contiguity; words are part of language, therefore the PART FOR WHOLE metonymy will be activated most of the time. In some cases the metonymy is lexicalized, for example, when we take the lexeme to mean the text of a song as in:

(20) I know, it was fantastic. erm but I I think er it was the words they were singing. (BNC: fffxlfxr 97)

I have classified the examples into three main groups based on the three core elements of the communicative process: the message, the speaker and the listener, which are the three elements that every speaker is conscious about.

\subsection{The message}

\subsubsection{Words in the conduit}

In Reddy's conduit metaphor theory words are containers where we put ideas. Lakoff also develops this idea: "THE MIND IS A CONTAINER, IDEAS ARE ENTITIES, and communication involves taking ideas out of the mind, putting them into words, and sending them to other 
people" (Lakoff 1987: 450). Goossens (1994: 387) actually claims that containment is perhaps the main ingredient in the conduit metaphor, which "implies that it should be more adequate to speak about the container metaphor than the conduit metaphor" (1994: 388). As discussed above, the conduit metaphor is a means of reifying our view of the communicative process which involves a complex system of metaphorical mappings. The following metaphors are part of this model: COMMUNICATIONIS SENDING IDEAS, IDEAS ARE OBJECTS and WORDS ARE CONTAINERS. We probably will not find linguistic expressions with all these associations activated at the same time. It is possibly the idea of motion the one which prevails in English linguistic expressions, as proved by Rudzka-Ostyn (1988a); perhaps due to intrinsic linguistic reasons (cf. Martínez Vázquez 2005).

In our corpus there are several examples of words conceived as moving objects. These examples can be understood as linguistic manifestations of the COMMUNICATION IS SENDING IDEAS metaphor:

(21) However they can be used just as "wallpaper" to fill the screen while the words carry the message. (BNC: flfulfua 25)

(22) ....and usually the words didn't make any sense, and they passed through his mind so quick (BNC: flfylfyy 92)

(23) ...no presence that disturbs me no other voices, words-as-strangers flaring through the hiss of distance (BNC: flfulfu5 19)

The WORDS ARECONTAINERS metaphor, however, does not appear in linguistic expressions as frequently as expected. In our corpus, there are 48 occurrences of the set phrase "in other words". This phrase is the most frequent cluster found in two larger corpora of around 10.000 examples each: corpus B with 610 occurrences and corpus $C$ with 747 (see appendix A). This expression suggests the idea of containment because of the presence of the preposition in; however a closer analysis reveals the phrase as a conventional means of finding a much more precise manner of explaining things. As a gain-time device it is often repeated:

(24) But if the goods are faulty what you're entitled to by law is money back. A cash refund in other words. So that you're, in other words you either, you're, by having the money back in your hand you are then restored to the position you were in before you bought the goods in the first place.

The phrase is also found six other times with the possessive but, as in the previous examples, without necessarily implying an idea of containment:

(25) In your own words describe the image that this extract gives. (BNC: flfulfu3 14)

Another example where words might be understood as containers is (26). However, another possible reading would lead us to interpret the phrase as expressing state rather than 
place, as "in writing", without an idea of containment.

(26) The History essay is a logical argument in words which demonstrates historical knowledge, skills and understanding. (BNC: flfulfu3 60)

In other examples with the phrase "in words", (27) and (28), I find it also difficult to detect a clear idea of container, while it seems easier to understand them as expressions of state, as in the phrase "in linguistic form" or instrument, as in "with words".

(27) Learned gestures can often be restated in words. (BNC: flfulfua 57)

(28) ...my aim in the book was to describe these mental images in words, with the help of familiar analogies and a few diagrams. (BNC: flfylfyx 23)

The preposition "in" is frequently used in an extended sense expressing state, in phrases like in love, in trouble, in ink or, in italics (cf. Downing and Locke 1992: 600 and Quirk et al. 1985: 685, among others). This association originates from the primary metaphor STATES ARE LOCATIONS (Lakoff and Johnson, 1999). Primary metaphors are the basis for many figurative associations, many of which, as Grady (2005) claims, "we hardly notice are not literal". I suggest that speakers using expressions of the type "in words" are not clearly conscious of the original idea of location implied by the preposition "in" but rather relate the phrase to similar expressions like "in ink" or "in italics", so that state rather than containment comes to their minds.

Besides, words are frequently taken as instruments used to communicate. In corpus B with ranks as the forth most frequent preposition introducing the lexeme words, (341 occurrences); in corpus $\mathrm{C}$ it appears in fifth position with 251 occurrences. Another instrumental reading is detected in the presence of the verb use, which is the first most frequent verbal collocate in both corpus B (195 occurrences) and C (196 occurrences).

One of the most cited examples of the container metaphor probably involves the phrase put into words. Surprisingly, in a search of the entire BNC corpus (100 million words), there appeared only 56 occurrences of this phrase. The following examples illustrate this use:

(29) He felt a vague disappointment which he couldn't put into words. (BNC: hlhththty 86)

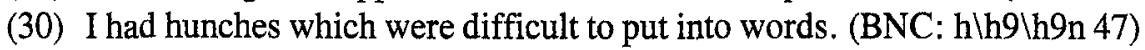

(31) "I- "It was hard to put into words what had been until so recently just a thought at the back of her mind. . (BNC: $j \backslash j x \backslash j x v$ 93)

(32) Jenny knew more than she was prepared to put into words. (BNC: flfs $\backslash f s 946$ )

(33) Then, in her attempt to experience more closeness to her husband and to drive him to understand what she felt like but could not make conscious or put into words, she did to him what had been done to her. (BNC: $b \backslash b n l b n f 70$ ) 
always something unreachable like thoughts or feelings, as found in (29)-(33). The expression means "define", "explain", as a way of reifying the abstract, as defined in Collins English Dictionary, "to express in speech or writing as well as thought". So the phrase as is presently used may simply activate in the speaker's mind the formal part of the combination form-meaning that each linguistic unit entails. Lexical items denoting linguistic units, as Goossens (1994: 392) signals, "conceptualize the combination that is characteristic of all the symbolic units of natural language, viz. the combination of form and meaning ('content')." As such, they can be used metonymically for either of these two parts. This mapping as Goossens claims is "in principle, independent of the container metaphor." Besides, we could claim that as a fixed expression it is used automatically, and that the speaker/listener is not aware of any figurative meaning. As Curse (2000) points out:

If, however, a metaphor is used sufficiently frequently with a particular meaning, it loses its characteristic flavour, or piquancy, its capacity to surprise, and hearers encode the metaphorical meaning as one of the standard senses of the expression. (2000:42)

\subsubsection{Words are quantified}

The lexeme word is a count noun, therefore, it should not surprise us to find it with the indefinite determiner $a$. However, the metonymy wORDS ARE SPEECH is generally activated. When words stand metonymically for speech, the lexeme becomes a conceptually mass and abstract notion. As discussed in section 1.1, the PART FOR WHOLE metonymy helps delimit an unbounded element. Likewise, speech may be delimited by taking a part of it, a word. The expression have a word appears 26 times in our oral corpus; 66 in corpus $B$ and 47 in corpus $C$. It usually means more than just a brief interchange of communication, typically uttered in confidence; it also implies that it will bring about a change of some type, as in the following examples:

(34) But where are we gonna go before Friday love? Mum just have a word with dad and I'll find somewhere to go! (BNC: $k \backslash k c \mid k c f 42$ )

(35) Oh it's bloody dangerous, very dangerous stuff! Twenty five. Well at least he can have a word with him about it and see what and he can do (BNC: $k \backslash k c \mid k c f)$

The minimizing effect is stressed by the use of little, which produces an ironic effect in the following example:

(36) Ah! Oh! Policeman having a little word with a sa, motorcyclist down here by the looks of it! Where? On the corner. (BNC: $k \backslash k c \mid k c b$ )

Speech can also be quantified by larger amounts as in (37) and (38). When speech is ceaseless the source domain is a river, (40)-(41). This metaphor is also suggested in another 
example with the opposite image, the idea that when you do not have words/ideas you dry up, (42).

(37) I mean I hated him, I really did and when he turned round and he said ooh Keith wants a few words I said to Elaine, look shit's gonna be it (BNC: $k \backslash k c \backslash k c p 71)$

(38) ...there are an awful lot of words left over! (BNC: flfulfu3 30)

(39) ... it forces you to reduce the bulk of words and yet preserve the essential meaning of the text. (BNC: fifulfu3 31)

(40) These points are lost to the reader in the torrent of words. (BNC: flfulfu3 75)

(41) Jack listened, and after a while he began to make out the quick flow of words. (BNC: blbp $\backslash$ bpd 60)

(42) Yeah, if they come up to you with a microphone and say would you like to say a few words for the television programme yourself I wouldn't $I$ ' $d$ dry $u p$ I wouldn't know what to say (BNC: $k \backslash k c l k c s ~ 17)$

\subsubsection{Words are shaped}

Words in writing may be measured as long or short words without using any figurative device, as in (15) above. However, words can also be given a figurative size. Recall the use of a little word in (36). In our corpus there are three occurrences of the phrase "big words", referring to difficult words, probably based on the fact that English words are short, whereas words coming from other languages, typically from Latin or Greek, are longer and are also considered superior. The primary metaphor IMPORTANT IS BIG (Lakoff and Johnson 1999:50), which associates importance with size explains the appearance of "big" instead of "long" in this expression. ${ }^{4}$

(43) Excuse me just because the tape's on there's no need for you to use big words like prognosis. (BNC: $k \backslash k d \backslash k d 039$ )

(44) Antidisenstablishmentarialism. Oh, not your big word. See that's her biggest word she knows. (BNC: $\mathrm{k} \backslash \mathrm{kp} \backslash \mathrm{kpg} 87$ )

Primary metaphors are acquired in our early childhood automatically and unconsciously. As Lakoff and Johnson state (1999:57):

We have a system of primary metaphors simply because we have the bodies and brains we have and because we live in the world we live in, where intimacy does tend to correlate significantly with proximity, affection with warmth, and achieving purposes with reaching destinations.

Primary metaphors are not based on similarity or analogy, but on experiential correlation; they are entrenched conceptual associations motivated by recurrent correlations in experience and they can be combined to larger structures building complex metaphors. 
(Grady 1997, 2005 and Grady, Oakley and Coulson 1999).

\subsubsection{Words in isolation}

Besides the major framework of the conduit metaphor, in which ideas and feelings are contained in words or in human heads, Reddy proposes another minor framework which "overlooks words as containers and allows ideas and feelings to flow, unfettered and completely disembodied, into a kind of ambient space between human heads" (1979: 291). He conceives three categories in this minor framework, one of which views thoughts and feelings as existing independently of human beings. In our corpus we find the following examples were words work by themselves as isolated from the speaker/writer: ${ }^{5}$

(45) And we mustn't let words and other fashionable elements, become too dominant. (BNC: flfylfyb 50)

(46) Words like these occur constantly in historical writing. (BNC: flfulfu3 21)

(47) But the words on the page didn't have the power to blot out the crack of hunting guns she was beginning to hear again inside her head, nor make her forget the sight of the blood trails on the hot plain. (BNC: f\fulfu8 59)

\subsection{The speaker}

\subsubsection{Words inside the body}

Words are sometimes seen as coming out of another container: the body. Since "each of us is a container" as Lakoff and Johnson -quoted above- state, and words contain ideas which are products of our mind, it is common to find words as created inside our body and coming in and out of it (48)-(52), even with our breath (53).

(48) These words keep coming into my head!" (BNC: clcalcad 73)

(49) The words had all tumbled out, one upon another. (BNC: clc8lc8s 29)

(50) Almost before the words had left her mouth, she felt a stab of excitement. (BNC: alaslasd)

(51) We'll take the very words out of your mouth (BNC: flfulfu6 43)

(52) Nathaniel Sherman jabbed a thumb against his own chest and his words came out in a fierce undertone. (BNC: f\fulfu8 77)

(53) Don't breathe a word. (BNC: k\kc|kce 53)

There are two examples in our corpus in which the speaker keeps the words inside this body-container.

(54) I lean close, as if to trigger that drained face or dredge whatever words she might be holding still for me to hear (BNC: flfulfu5 28) 
(55) What was she saying, Irene, what was she going on about, in words half saved, half drowned - in gasps and whispers? (BNC: flfylfyv 22)

Another metaphor in our corpus relates words to food, which is not strange since they share a common domain: the mouth, which is viewed as a container for both words and food.

(56) Do the characters speak very quickly? Do they swallow their words? (BNC: flfulfua 22)

(57) ...either one way or the other, and er er er you didn't er you didn't m mince words about it, did you not, I mean you. (BNC: flfylfyj 24)

(58) I' $m$ I think I'm talking about the words first of all. I think we can all get the flavour of what the message is (BNC: flfylfyb 45)

Kövecses (2002: 72-74) represents the perceived structural similarities between the abstract concept of idea and the concrete concept of food which motivate the metaphor IDEAS ARE FOOD in the form of the following mappings:
(a) cooking thinking
(b) swallowing _accepting
(c) chewing_considering
(d) digesting _ understanding
(e) nourishment_mental-well being

The food metaphors which appear in examples (56)-(58) entail the following mappings, which are also based on the structural similarities between an abstract element, word, and a concrete entity, food:

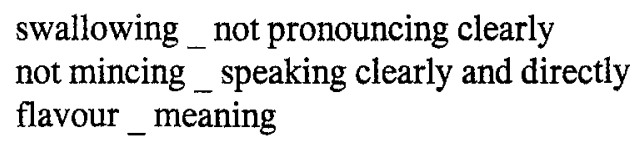

This food metaphor, like the communicative act, is bidirectional. Thus, the speaker may swallow his/her words, meaning that s/he keeps them for him/herself; and conversely the listener may not swallow them, or allow them to enter his/her mind, thus not believing them.

In a more elaborate metaphor, words inside the body are perceived as threads, as in

(59), though this source domain is not necessarily located inside the body, as in (60).

(59) Bored, sullen, resigned, I listened. Then suddenly the words wove within me, transporting me through another's imagination. (BNC: flfulfu 743 )

(60) It was only years later, after becoming a Christian, that I was able to clothe that feeling with words. (BNC: $b \backslash \mathrm{b} 2 \backslash \mathrm{b} 2 \mathrm{~g} 65$ ) 
The clothe metaphor in (60) is another mapping relating the abstract (words) with the concrete (clothe). This association is not new as we can see in the definition supplied by the OED for clothe (8b) "To put (thoughts or ideas) into words; to express in (or with)" and illustrated by the following examples:

1671 Milton P.R. ii. 65 Some troubl'd thoughts which she in sighs thus clad. 1673 Ray Journ. Low C. Pref., Mr. Willughby's voyage which he himself would doubtless have cloathed with better language.

1741 Watts Improv. Mind (1801) 212 Clothe those ideas with words.

1771 Junius Lett. Lxi. 316 Clothe it in what language you will.

177981 Johnson L.P., Dyer Wks. IV. 212 Cloathing small images in great words. $1850^{-} \mathrm{H}$. Rogers Ess. I. iii. $102 \mathrm{He}$ has clothed the determinate quantities of arithmetic in the universal symbols of algebra.

In (59) we find a different type of association; language is viewed as a web whose threads are words woven together. Notice that the verb weave shares its root with web. The web metaphor suggests the image of a construction made out of threads which are linked together. The most prototypical image is probably that of a spider web and the main ingredient is that of a strong interconnection. The metaphor WORDS ARE THREADS WEAVING A WEB directly relates to the etymological meaning of syntax, from Greek $\sigma \nu v \tau \alpha \xi \xi$, and Latin constructio, which means to link, to join together.

\subsubsection{Words belong to the speaker}

Quite frequently language appears as owned by the person who utters it, as if the words, once uttered, belong to the person who pronounced them, (61). This emphasizes the fact that speakers create their own discourse, since ideas may be transmitted in many different ways. In our corpus there are 24 examples of the lexeme introduced by a possessive determiner (5\%); a look at the collocates of corpus B shows his as the third most frequent first word used to the left of the lexeme word, 236 cases. It is interesting to note, however, that her follows in position 15 with only 64 occurrences. The possessive is sometimes used especially with "very" to show the exact words without change or manipulation, (62). A similar expression related to literalness is word for word, found once in our corpus, (63).

(61) Whose words are these? (BNC: fk $\backslash \mathrm{kclkcu} 93$ )

(62) It was urgent - a matter of extreme urgency, a royal summons, his very words: official business and no questions asked (BNC: flfulfu6 9)

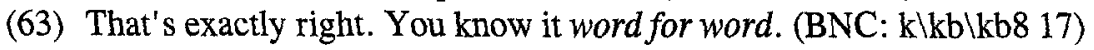

As objects, words can also be weighed, which is figuratively used to express careful analysis in (64). 
(64) The phrasing got so slow and emphatic that you knew that she wanted you to listen to and weigh up every single word (BNC: a arlar2 64)

In the conduit metaphor words are presented as moving objects, travelling form the speaker to the listener. According to this view, an object which is perceived as heavy will move with difficulty, therefore causing communication problems, as in (65). This mapping is an elaboration of the primary metaphor DIFFICULTIES ARE BURDENS (Lakoff and Johnson, 1999) or DIFFICULTY-AS-HEAVINESS (Grady 2005). In (66), the speaker equates his failure to communicate to difficulty in moving the words around.

(65) There is a heaviness of words not said between us, dragging us higher though the air (BNC: f fulfu5 1)

(66) She proved immune to my lightheaded but rather leaden gallantries, the words so hard to shift around. (BNC: flfylfyv 83)

\subsubsection{Words are ideas}

The container metaphor presents words as containing ideas; sometimes the word is directly taken as the idea that is contained in it. Lakoff and Turner term it the WORDS STAND FOR THE CONCEPTS THEY EXPRESS metonymy.

(67) Oh. Well I And I, and I believed every word of it. Ha! Ha! Well, I couldn't know that, I didn't know. (BNC: $k \backslash k c \backslash k c h$ 72)

Sometimes words share the human features of the speaker:

(68) ...you couldn' $t$ tell if each word was freighted with anger, or bitterness, or joy (BNC: alar(ar2 64)

(69) ...these are vital because we tend to use words in a fraudulent manner. Words demand to be treated with great truth. (BNC: blbmlbmy 11)

According to Lakoff and Johnson the meaning of words is objective, and if communication is not felicitous it is due to subjective errors:

Meanings are objects. Linguistic expressions are objects. Linguistic expressions have meanings (in them). In communication, a speaker sends a fixed meaning to a hearer via the linguistic expression associated with that meaning. On this account it is possible to objectively say what you mean, and communication failures are matters of subjective errors: since the meanings are objectively right there in the words, either you didn't use the right words to say what you meant or you were misunderstood (Lakoff and Johnson 1980: 206).

In our corpus words are described as right or wrong: 
(70) That's okay, she's also given me the right words to use to put it through urgently, okay (BNC: $k \backslash k b \backslash k b 791)$

(71) Very, I would say it's not depressing that's the wrong word (BNC: $k \backslash k c \backslash k c p$ 63)

However, communication does not appear to be this simple. Even though sometimes language is seen as intuitive, as in (72), it usually appears as something that does not come automatically. On the contrary, it implies a considerable effort on the part of the speaker, who has to search for the words that best fit the concept s/he wants to transmit, (73)-(76). The result of the search may also vary, (77).

(72) Grim and forbidding were the two well-used words that came to mind as she looked up at the building for the first time (BNC: flfylfyy 81)

(73) He looked at her then. You like it? It's- She searched for the words. (BNC: flfylfyy 1)

(74) She had chosen her words with calculation in an attempt to break the impersonal barrier... (BNC: flfulfu8 49)

(75) Mhm. Erm he forgets, he knows the word but he can't get it Get out. out. Yeah. (BNC: $k \backslash k b \backslash k b 837$ )

(76) They said outright what I could not find words for. (BNC: flfulfu7)

(77) GUIL: You'd be lost for words. ROS: You'd be tongue-tied. GUIL: Like a mute in a monologue (BNC: flfulfu6)

Our examples reveal a general tendency to view language as obscure, with words not transmitting a precise meaning, as mathematical symbols, but rather presented as ambiguous elements which may hide something:

(78) Such words can hide a wealth of meaning. (BNC: flfulfu3 55)

(79) Metaphors, descriptive words and even nouns can lead to vagueness and ambiguity for the reader (BNC: flfulfu3 21)

(80) Reject those words which obscure rather than clarify meaning-words which are only present for purposes of style, linguistic sense (BNC: flfulfu3 86)

\subsubsection{Words are promises}

Words once reified are also treated as tokens which comprise a promise. As tangible elements they are given, taken, kept, broken, (81)-(83), yet they are valued as true or false,

(84) The possessive introducing them signals the person who makes the promise.

(81) "But I've got to keep looking. After all, I did give my word. (BNC: flfr $\backslash$ frm 16)

(82) ...something like these accounts have erm have been audited but only erm we have taken the word of $\mathrm{Mr}$ that what he said is right. (BNC: $\mathrm{klkclkct} \mathrm{15)} \mathrm{he} \mathrm{was} \mathrm{able} \mathrm{to}$ keep his word. (BNC: alaclace 47) 
(83) ...his support was sufficiently strong to withstand accusations of breaking his word and of disloyalty (BNC: alaplape 5)

(84) The man was true to his word. (BNC: b $\backslash b m \backslash b m n$ 76)

\subsubsection{Words are limited}

Failure to communicate is sometimes expressed as a lack of language resources. The speaker claims that there are things which cannot be expressed through language, underlining the lack of correspondence between signs and reality, with the former being limited while the latter is unlimited. This failure in communication is illustrated in examples (85)-(87). In corpus $B$ and $C$ we find clusters like "there is/was no word", "there are/were no words", which illustrate the speaker's perspective.

... there were no words that could easily describe the helpless terror that she felt as the side-gate opened before them and the ambulance had driven through. (BNC: flfylfyy 81 )

(86) Pete and me had been together for eleven months and loved each other more than words could say. (BNC: flfulfu1 20)

(87) What do you expect me to say? But her gaze was beyond words; even if he said nothing at all, she could read him with ease. (BNC: flfylfyy 98)

\subsection{The listener}

\subsubsection{Words are balls}

Most of our metalanguage concentrates around the speaker, but sometimes the emphasis shifts to the listener. In this section we will discuss some linguistic expressions in which the listener is particularly implied. In line with the conduit metaphor, which involves the metaphors IDEAS ARE OBJECTS and COMMUNICATION IS SENDING IDEAS, some expressions relate to the way the listener receives these ideas/words as objects "caught", "missed" or "picked up" almost as in a ball game, (88)-(90). The primary metaphor which motivates these expressions is UNDERSTANDING IS GRASPING (Lakoff \& Johnson 1999).

(88) Are you in pain? The reply is a blur of distress the only words I catch (not wanting to) but - doctor - I don't know... (BNC: fffulfu5 73)

(89) She misses more words out than she gets in! And she just writes over them in, in pen! (BNC: $k \backslash k b \backslash k b 177$ )

(90) ... when I'm in Italy, I, I can't speak Italian very well, but when I' $m$ there a week, I pick up words very quickly and although I know my grammar isn't perfect, I can form sentences (BNC: klkclkcv 19) 


\subsubsection{Words are weapons}

Probably one of the most pervasive metaphors related to the listener is WORDS ARE WEAPONS. In (91) and (92) words have stings. In (93) the attack is not physical.

(91) Nick said, but very gently to take the sting out of the words, "You're not his mother." (BNC: flfulfu2 99)

(92) Stung by his father's words, Chuck dashed forward across the clearing. (BNC: flfulfu8 78)

(93) Duclos' eyes narrowed as he registered the undisguised threat in the recruiter's words; then he forced a laugh to his lips. (BNC: Ifulfu8 92)

In (93), we find another concept associated to words in their relation to the listener: the fact that the effect the speaker wants to produce on the listener is usually hidden. Sometimes words are played with to influence the listener, as in advertisements:

(94) Many advertisements play with the meanings of words. (BNC: flfulfua 29)

The persuasive effect of words is also present in other expressions:

(95) These words, I'm glad to say, had a relaxing effect on her. (BNC: flfylfyv 23)

However, in an oral corpus metaphors are not very elaborate. The more complex metaphor around the listener in our corpus is (96) where the word is taken as a medicine that is dropped in the listener's ear as a poison used to bring about the actions desired by the speaker, with reminiscences of the murder of Hamlet's father.

(96) A word dropped in the right ear, Nelly told herself, might bring her the job (BNC: alasłase 28)

\subsubsection{Words are keys}

Another metaphor linguistically expressed in a set phrase is key word to signal words which are more important, (97). In this sense, the image is not that of a container which may be opened; the word as key will be used to open something else, the meaning of the whole message. This conceptual metaphor can appear in other linguistic forms, as in (98).

(97) To discover the main points in this writing you must identify the key words and phrases that create the mental picture. (BNC: flfulfu3 14)

(98) Words could open these strange worlds again. (BNC: flfulfu7 44)

In contrast to this concept of words as keys other words are presented as superfluous: 
(99) Your notes, however, should strive to be concise and need to be stripped of unnecessary words. (BNC: fffulfu3 42)

(100) ... many documents, especially from the nineteenth century, contain redundant words which only serve to confuse. (BNC: flfulfu3 85)

\section{Concluding remarks}

In order to understand reality we try to delimit it. This constant delimitation procedure has been explained in terms of containment. Lakoff and Johnson state that we put boundaries, "marking off territory so that it has an inside and a bounding surface", even when there is no natural physical limits. They relate this practice to what they consider one of the most basic human instincts: "territoriality" (1980: 29). As an important, mostly abstract, facet of human nature, language is also reified in terms of other more concrete elements surrounding us, but not necessarily as physical containers where ideas are thrown, as implied in the conduit metaphor. In our corpus analysis of the lexeme word we have found a richer variety of figurative associations: words are delimited in terms of physical objects, and as such they are quantified, weighed or shaped. They are seen as moving elements, coming out of the speakers mind/mouth and directed towards listeners who, as in a ball game, may catch them or miss them.

As a social activity communication involves a group formed by at least two participants: speaker and listener, who interrelate through language. Our speech acts may pursue different goals as observed by Jackobson. The different functions of language also influence the type of figurative language we construct. Many figurative expressions about language turn around the problems presented for the speaker: words are not precise, they do not easily match our thoughts and sometimes there is no way of finding a correspondence between sign and reality. Communication concentrated around the message views words as isolated from the speaker-listener and working on their own. Figurative linguistic expressions around the listener show words as either helping or hindering decodification. Sometimes words are used to hurt the listener or to influence him/her.

Our corpus analysis shows a general perception of language as not precisely bounded. This lack of accuracy is somehow incompatible with the container image, since a container suggests the idea that something is clearly delimited. Speakers reveal certain confusion about language, they do not believe in the truth and clarity of language, they rather believe that language is obscure and sometimes deceptive. In such a picture words are seen more as "standing for" than as "containing" anything.

It has been claimed that many metaphors develop from metonymies (Goossens 1990 and Barcelona 2003a). Linguistic action metaphors are not an exception. The different metaphors appearing in our corpus involve a first part-whole mapping: the WORDS ARE LANGUAGE/SPEECH metonymy. We have also observed some Primary Metaphors which underlie some of the linguistic action metaphors in our corpus. 


\section{Notes}

* The research presented in this paper is part of the project "Metáfora y Metonimia en el Metalenguaje" (BFF 2003-04064) funded by the Spanish Ministry of Science and Technology and the FEDER (Fondo Europeo de Desarrollo Regional) Program.

1. I define this study as a "corpus-based approach" following previous work on this topic by Goossens et al. (1995: vii), who define their studies in this way: "We would like to characterize our book as empirical, because the research it presents is corpus-based, in the sense that it relies on language data which have been gleaned systematically from a variety of sources". On the advantages of corpus-based research on figurative language see Deignan (1999), Deignan and Potter (2004), and Charteris-Black (2004).

2. As an anonymous reviewer correctly observes, the PART FOR WHOLE metonymy is associated to concrete nouns, which invoke entities made up of a heterogeneous number of parts, whereas figurative expressions with mass nouns are better defined as cases of MATERIAL FOR OBJECT. Ruiz de Mendoza and Pérez (2001) refer to this mass for count association as the MATERIAL FOR ENTITY (CONTAINING/HOLDINIG THE MATERIAL) metonymy in examples like $I$ would like two beers, please.

3. A task which has already been performed by Vanparys (1995), although centred on verbs.

4. I owe this remark to an anonymous reviewer. For more information about primary metaphors see Grady (1997) and (2005), and Lakoff and Johnson (1999).

5. A reviewer observes that the 'power/dominance' dimension' should be mentioned in the explanation of these examples and offers the proverb The pen is mightier than the sword. It is interesting to note that the opposite is also true Actions speak louder than words as in the following example: Any actions that are speaking louder than his words? (BNC: $\mathrm{klkr} / \mathrm{krl}$ 87). It seems to me that in modern society words are somehow decreasing their power. Example (47) illustrates this loss. Another element that overrules the power of words is image (cf. A picture is worth a thousand words).

\section{Works Cited}

Barcelona, Antonio (2003a): "On the plausibility of claiming a metonymic motivation for conceptual metaphor". In A. Barcelona, ed., Metaphor and Metonymy at the Crossorads. A Cognitive Perspective. Berlin: Mouton de Gruyter: 31-58.

. (ed.)(2003b): Metaphor and Metonymy at the Crossorads. A Cognitive Perspective. Berlin: Mouton de Gruyter.

BNC [BRITISH NATIONAL CORPUS] (1995): Oxford University Computing Services for the BNC Consortium. (Version 1.0). Oxford: Oxford University.

Cameron, L. and G. D. Low (eds.)(2004) Researching and Applying Metaphor. Cambridge: Cambridge University Press.

Carlon, K, K. Davidse and B. Rudzka-Ostyn, (eds.)(1994): Perspectives on English. Studies in Honour of Professor Emma Vorlat. Leuven: Peeters.

Charteris-Black, Jonathan (2004): Corpus Analysis to Critical Metaphor Analysis. New York: Palgrave Macmillan.

Cobuild [Sinclair, John] (ed.)(1987): Collins Cobuild English Language Dictionary. London: 
Collins.

Cruse, D. Alan (2000): Meaning in Language. An Introduction to Semantics and Pragmatics. Oxford: University Press.

Deignan, A. (1999): "Corpus-based research into metaphor." In L. Cameron and G. D. Low, eds., Researching and Applying Metaphor. Cambridge: Cambridge University Press.

Deignan Alice and Liz Potter (2004): "A corpus study of metaphors and metonyms in English and Italian". Journal of Pragmatics 36:1231-1252.

Dirven, René, Louis Goossens, Yvan Putseys, and Emma Vorlat (1982): The Scene of Linguistic Action and its Perspectivization by Speak, Talk, Say and Tell. Amsterdam: John Benjamins.

Downing, Angela and Philip Locke (1992): A University Course in English Grammar. London: Prentice Hall.

Quirk, Randolph, Sydney Greenbaum, Geoffrey Leech and Jan Svartvik (1985): A Comprehensive Grammar of the English Language. London: Longman.

Goossens, Louis (1990): Metaphtonymy: the interaction of metaphor and metonymy in expressions for linguistic action". Cognitive Linguistics 1-3: 323-340.

(1994): "Metonymy in the pipeline: another way of looking at the container metaphor". In K. Carlon, K. Davidse and B. Rudzka-Ostyn, eds., Perspectives on English. Studies in Honour of Professor Emma Vorlat. Leuven: Peeters, 386-394.

Goosens, Louis, Paul Pauwels, Brygida Rudzka-Ostyn, Anne-Marie Simon-Vandenbergen, and Johan Vanparys (eds.) By Word of Mouth. Metaphor, Metonymy and Linguistic Action in a Cognitive Perspective, Amsterdam: Benjamins.

Grady, Joseph (1997): "Foundations of meaning: primary metaphors and primary scenes". University of California, Berkeley: Ph.D. Dissertation.

(2005): "Primary metaphors as inputs to conceptual integration". Joumal of Pragmatics 37:1595-1614.

Grady, Joseph, Todd Oakley and Seana Coulson (1999): "Blending and Metaphor". In G. Steen and R. Gibbs, eds., Metaphor in Cognitive Linguistics, Philadelphia: John Benjamins, 101-124.

Jakobson, Roman (1960): "Linguistics and Poetics". In Sebeok, T.A, ed., Style in Language. Boston: Technology Press of MIT, 350-377.

Kövecses, Zoltán (2002): Metaphor. A Practical Introduction. Oxford: University Press.

Kövecses, Zoltán and Günter Radden (1998): "Metonymy: Developing a cognitive linguistic view". Cognitive Linguistics 9(1): 37-77.

Lakoff, George (1987): Women, Fire, and Dangerous Things - What Categories Reveal About the Mind. Chicago: University Press.

(1993): "The contemporary theory of metaphor". In A. Ortony ed., Metaphor and Thought. Cambridge: University Press, 202-251.

Lakoff, George and Mark Johnson (1980): Metaphors We Live By. Chicago: University Press.

. (1999): Philosophy in the Flesh: The Embodied Mind and its Challenge to Western Thought. New York: Basic Books.

Lakoff, George and Mark Turner (1989): More than Cool Reason. A Field Guide to Poetic Metaphor, Chicago and London: University of Chicago Press.

Langacker, Ronald W. (1987): Foundations of Cognitive Grammar, vol I: Theoretical Prerequisite. Stanford: University Press.

. (1991): Foundations of Cognitive Grammar, vol II: Descriptive Application. Stanford: 
University Press.

Martínez-Vázquez, Montserrat (2005): Communicative Constructions in English and Spanish". In Christopher S. Butler, $\mathbf{M}^{\mathrm{a}}$ de los Angeles Gómez-González and Susana M. Doval-Suárez eds., The Dynamics of Language Use: Functional and Contrastive Perspectives. Amsterdam: John Benjamins, 77-107.

Nerlich, Brigitte, David D. Clarke and Zazie Todd (1999): "Mummy, I like being a sandwich". In Klaus-Uwe Panther, ed., Metonymy in Language and Thought. Amsterdam: Benjamins, 361-383.

Otal, J.L., I. Navarro and B. Bellés (eds.)(2005): Cognitive and Discourse Approaches to Metaphor and Metonymy, Castelló de la Plana: Publicacions de la Universitat Jaume I

Ortony, A. (ed.)(1993): Metaphor and Thought. Cambridge: University Press.

Radden, Günter (1995): “The Ubiquity of Metonymy”. In J.L Otal, I. Navarro and B. Bellés eds.,

Cognitive and Discourse Approaches to Metaphor and Metonymy, Castelló de la Plana:

Publicacions de la Universitat Jaume I, 11-28.

Reddy, Michael J. (1979): “The conduit metaphor. A case of frame conflict in our language about

language". In A. Ortony ed., Metaphor and Thought, Cambridge: University Press, 284-324.

Rudzka-Ostyn, Brygida (1988a): "Semantic Extensions into de Domain of Verbal

Communication". In B. Rudzka-Ostyn, ed., Topics in Cognitive Linguistics, Amsterdam:

Benjamins, 507-553.

(ed.) (1988b): Topics in Cognitive Linguistics. Amsterdam: Benjamins.

Ruiz de Mendoza, F. J. and Pérez Hernández, L. (2001): "Metonymy and the Grammar:

Motivation, Constraints, and Interaction". Language and Communication 21:321-357.

Sebeok, Thomas A. (ed.)(1960): Style in Language. Cambridge, MA: MIT Press.

Seto, Ken-ichi (1999): "Distinguishing metonymy from synecdoche". In K-U. Panther and G.

Radden, eds., Metonymy in language and thought. Amsterdam: Benjamins, 91-120.

Steen, G. and R. Gibbs, (eds.)(1999): Metaphor in Cognitive Linguistics. Philadelphia: John Benjamins, 101-124.

Tenny, Carol (1987): Grammaticalizing Aspect and Affectedness, Doctoral dissertation, MIT, Cambridge, MA.

. (1994): Aspectual Roles and the Syntax-Semantics Interface. Studies in Linguistics and Philosophy 52. Dordrecht, Boston and London: Kluwer.

Vanparys, Johan (1995): "A survey of metalinguistic metaphors". In René Dirven,Louis Goossens, Yvan Putseys, and Emma Vorlat, eds., The Scene of Linguistic Action and its Perspectivization by Speak, Talk, Say and Tell. Amsterdam: Benjamins, 1-34.

Vorlat, Emma (1982): "Framing the scene of linguistic action by means of speak". In René Dirven,Louis Goossens, Yvan Putseys, and Emma Vorlat, eds., The Scene of Linguistic Action and its Perspectivization by Speak, Talk, Say and Tell. Amsterdam: John Benjamins, 9-35.

Wierzbicka, Anna (1987): English Speech Act Verbs. A Semantic Dictionary. Sydney: Academic Press.

Wyngaerd, Guido vanden (1998): “Aspects of (Un)Boundedness". Belgian Journal of Linguistics 12:77-102. 


\section{Appendices}

Appendix A. Frequency list of clusters with the noun word/s
Corpus B
Corpus C

\begin{tabular}{|l|l|l|l|}
\hline in other words & 610 & in other words & 747 \\
\hline of the word & 237 & the words of & 260 \\
\hline the words of & 209 & of the word & 229 \\
\hline in the words & 125 & in the words & 157 \\
\hline of a word & 98 & words of the & 111 \\
\hline a word with & 93 & the last word & 89 \\
\hline of the words & 88 & with the words & 83 \\
\hline words of the & 76 & a word of & 79 \\
\hline words in the & 75 & of the words & 74 \\
\hline have a word & 66 & a few words & 69 \\
\hline a few words & 61 & the word of & 67 \\
\hline without a word & 60 & a word with & 66 \\
\hline a word of & 56 & use of the & 58 \\
\hline the word of & 55 & that the word & 52 \\
\hline with the words & 54 & word of god & 52 \\
\hline in a word & 50 & the use of & 49 \\
\hline the meaning of & 47 & sense of the & 48 \\
\hline the last word & 46 & have a word & 47 \\
\hline the words in & 46 & not a word & 44 \\
\hline sense of the & 44 & the word is & 44 \\
\hline
\end{tabular}

Appendix B. Frequency list of the collocates of the noun word/s

Corpus B Corpus C

\begin{tabular}{|l|l|l|l|}
\hline the & 3840 & the & 3472 \\
\hline in & 1362 & of & 1568 \\
\hline a & 1170 & a & 1403 \\
\hline of & 1156 & in & 1233 \\
\hline other & 760 & other & 682 \\
\hline to & 574 & to & 590 \\
\hline and & 492 & and & 414 \\
\hline that & 360 & that & 358 \\
\hline his & 357 & his & 316 \\
\hline with & 341 & for & 270 \\
\hline is & 217 & with & 251 \\
\hline for & 205 & is & 188 \\
\hline not & 199 & as & 177 \\
\hline use & 195 & by & 163 \\
\hline
\end{tabular}




\begin{tabular}{|l|l|l|l|}
\hline by & 191 & not & 158 \\
\hline these & 174 & have & 155 \\
\hline last & 167 & or & 155 \\
\hline have & 151 & on & 146 \\
\hline on & 140 & use & 145 \\
\hline as & 139 & her & 142 \\
\hline
\end{tabular}

